\title{
Geographical areas
}

\section{The European Union, 1 January 2007}

Two countries which joined the EU on 1 January 2007

Ten countries which joined the EU on 1 May 2004

EU-15 members

Non-EU members

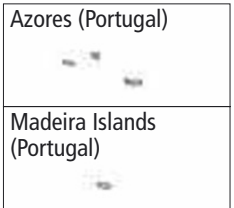

Canary Islands (Spain)

$$
\text { " } \left.\theta_{0}\right)
$$

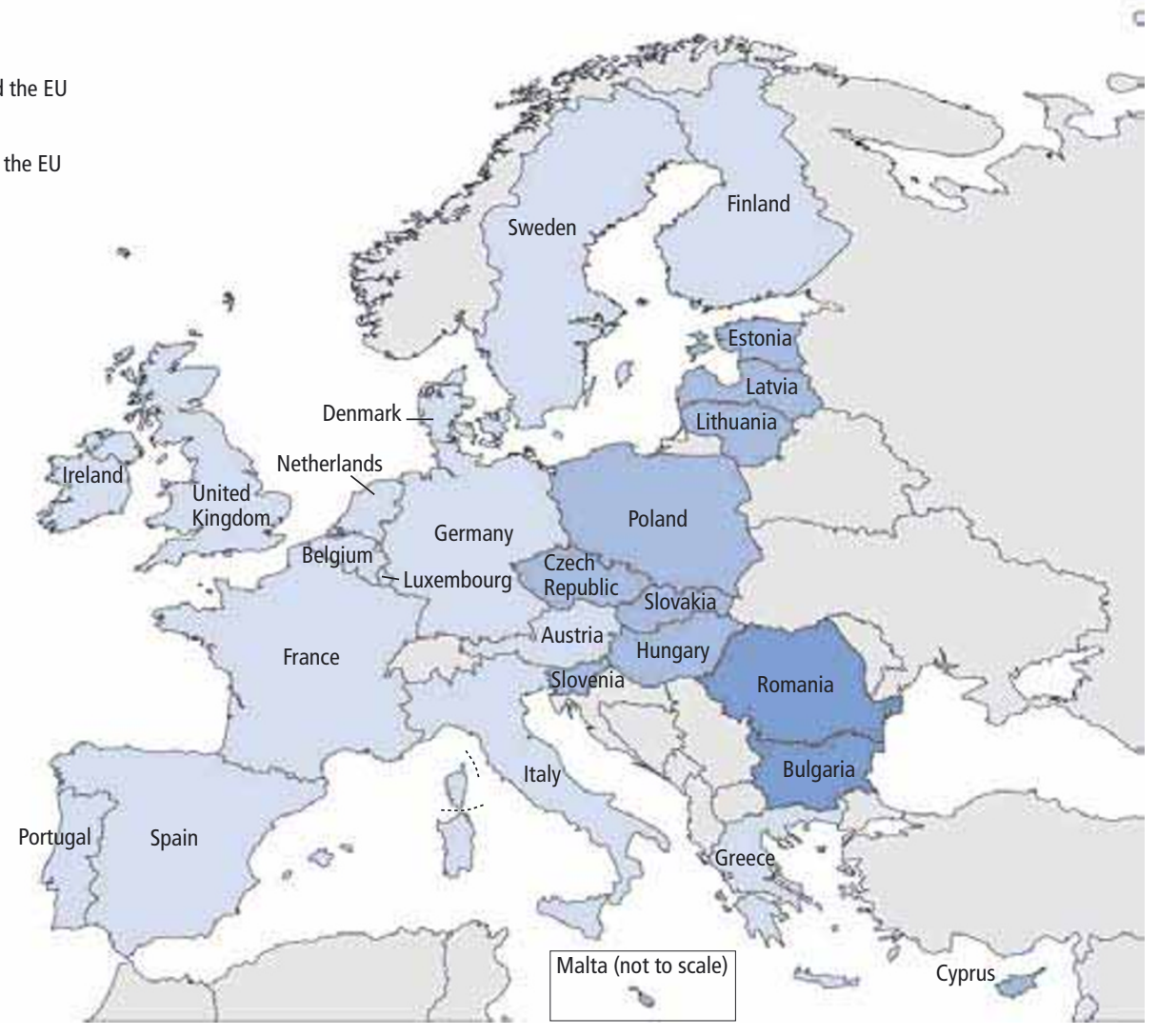

Countries on the Greenwich meridian line

Government Office Regions

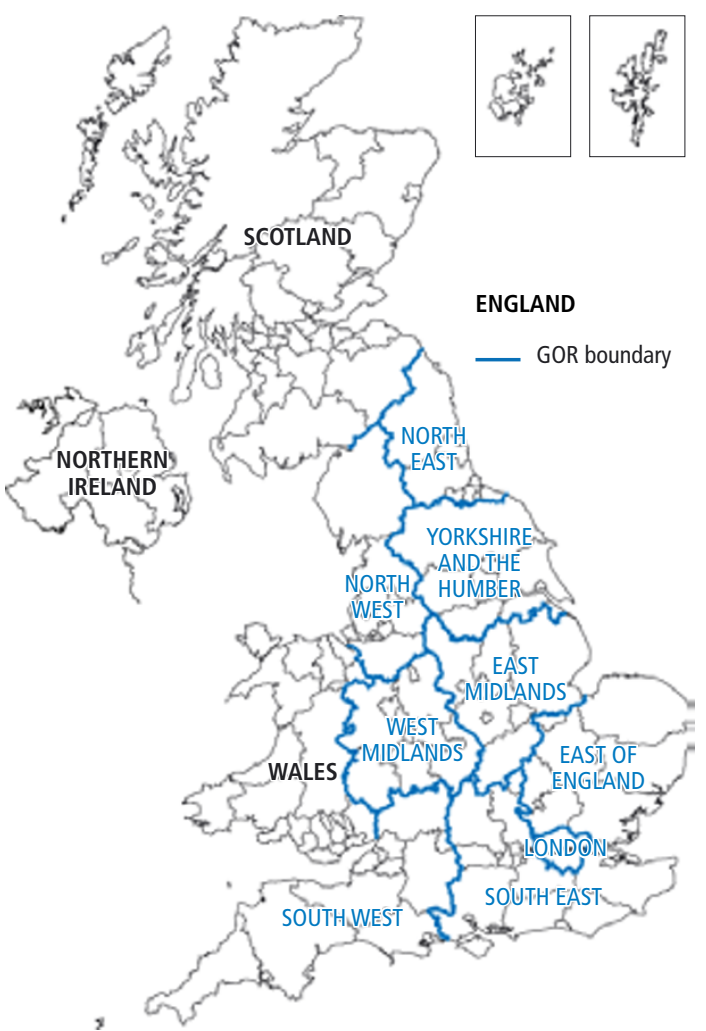



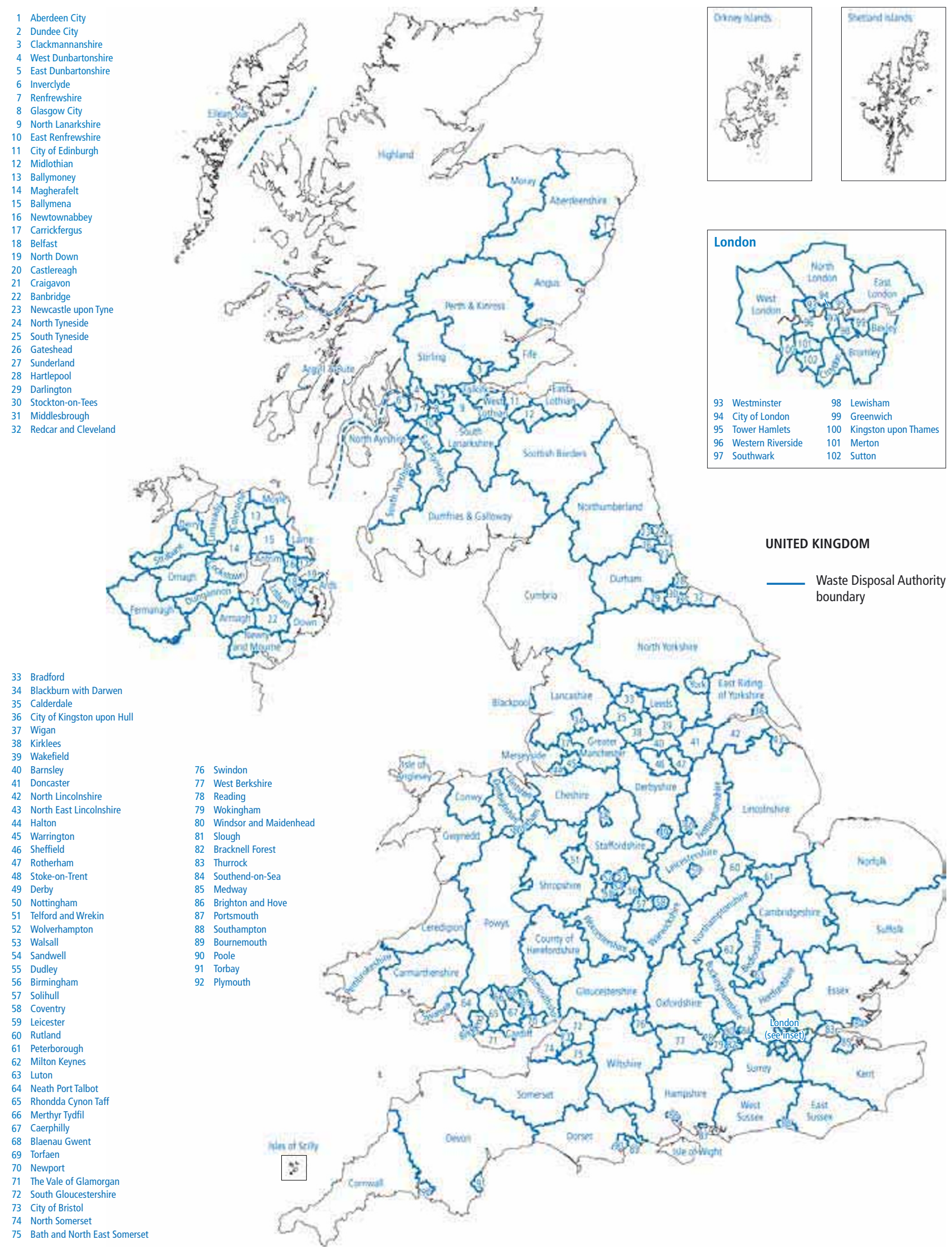
Local or Unitary Authorities ${ }^{1}$

1 Newcastle upon Tyne
2 Gateshead
3 Derwentside
4 Chester-le-Street
5 Sedgefield
6 Darlington
7 Stockton-on-Tees
8 Middlesbrough
9 South Ribble
10 Blackburn with Darwen
11 Hyndburn
12 Rossendale
13 Bury
14 Rochdale
15 Oldham
16 Salford
17 Manchester
18 Tameside
19 Ellesmere Port and Neston
20 Liverpool
21 Knowsley
22 St. Helens
23 Halton
24 Warrington
25 Trafford
26 Stockport
27 Kingston upon Hull, City of
28 North East Derbyshire
29 Chesterfield
30 Bolsover
31 Mansfield
32 Ashfield
33 Lincoln
34 Erewash
35 Broxtowe
36 Nottingham
37 South Derbyshire
38 North West Leicestershire
39 Hinckley and Bosworth
40 Leicester
41 Oadby and Wigston
42 Newcastle-under-Lyme
43 Stoke-on-Trent
44 East Staffordshire
45 South Staffordshire
46 Cannock Chase
47 Wolverhampton
48 Walsall
49 Tamworth
50 Dudley
51 Sandwell
52 North Warwickshire
53 Nuneaton and Bedworth
54 Coventry
55 Bromsgrove
56 Redditch
57 Worcester
58 Northampton
59 Wellingborough
60 East Northamptonshire
61 Cambridge
62 Norwich
63 Ipswich
64 Gloucester
65 Cheltenham
66 Bristol, City of
67 Bath and North East Somerset
68 Oxford
69 Reading
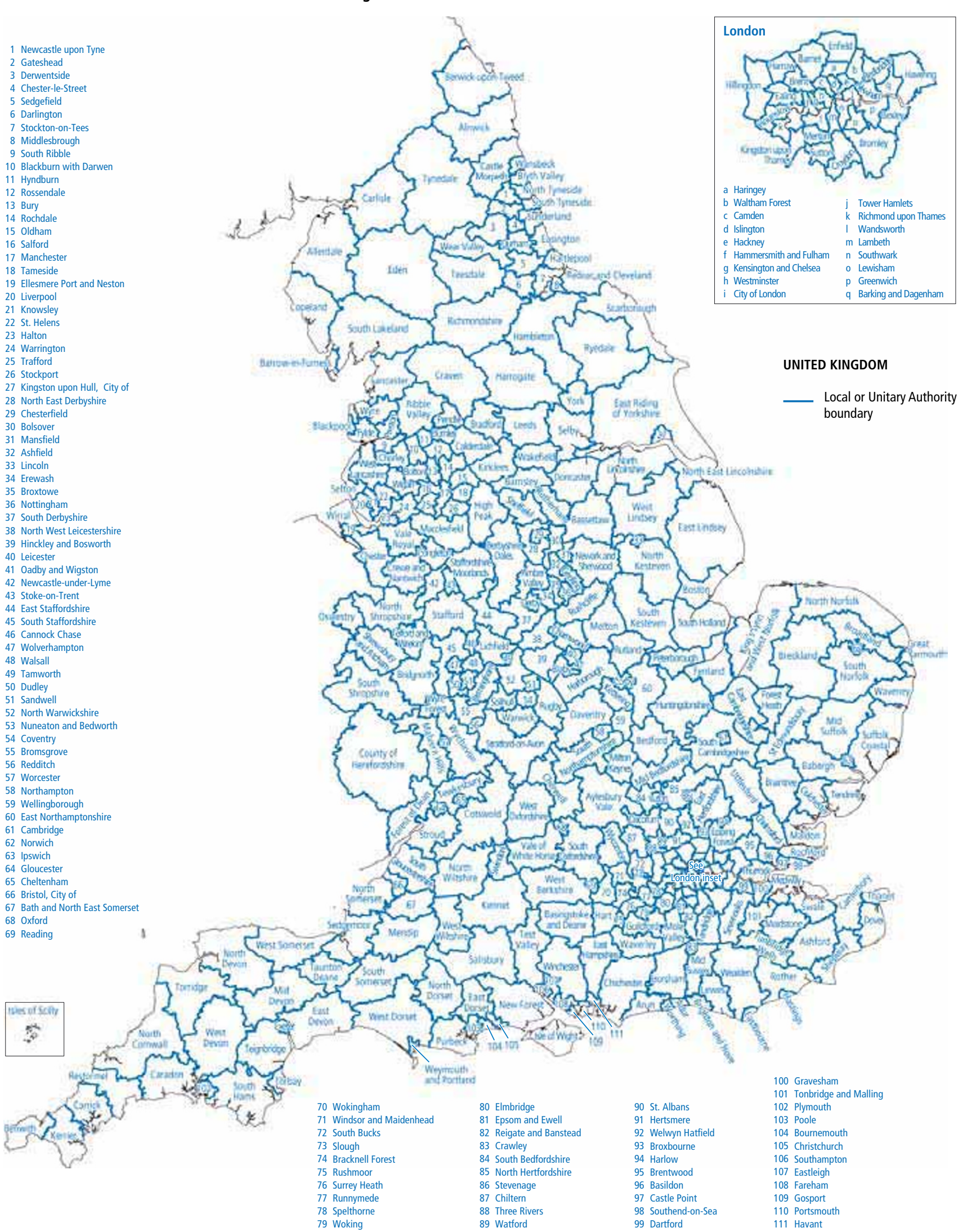

1 Local or unitary authorities in England, unitary authorities in Wales, council areas in Scotland and district council areas in Northern Ireland. 


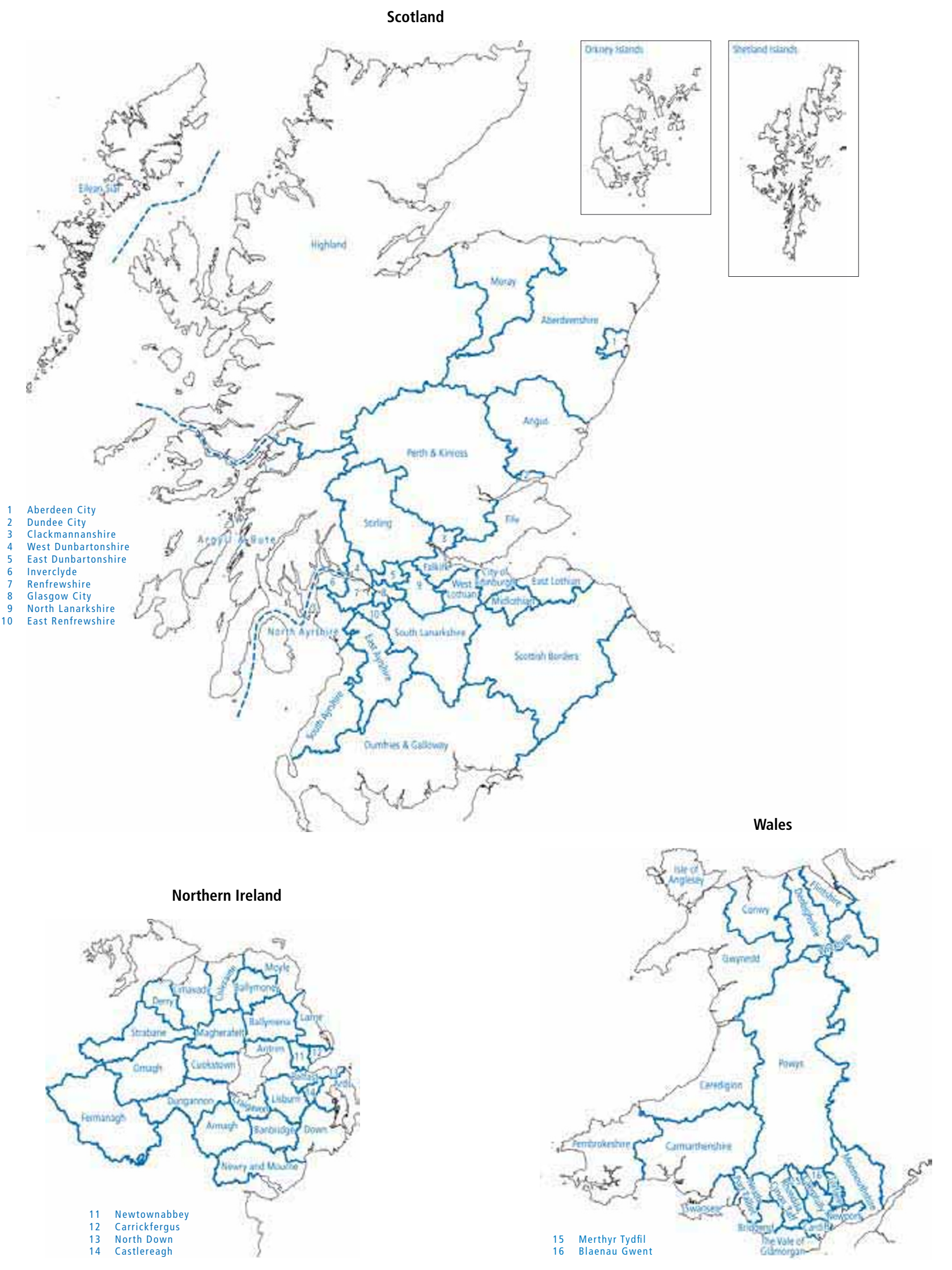

